\title{
KELAYAKAN MEDIA VIDEO PEMBELAJARAN PADA SUBMATERI SISTEM ENDOKRIN
}

\author{
Agus Astuti ${ }^{1}$, Ruqiah Ganda Putri Panjaitan ${ }^{2}$, Titin $^{3}$ \\ ${ }^{1,2,3}$ Pendidikan Biologi, Universitas Tanjungpura \\ Jalan Prof. H. Hadari Nawawi, Bansir Laut, Pontianak, Kalimantan Barat \\ e-mail: agusastuti15@gmail.com
}

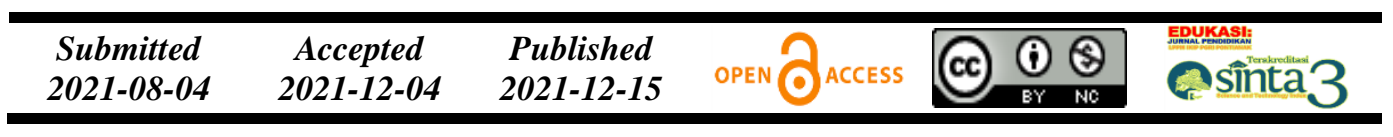

\begin{abstract}
Abstrak
Penelitian bertujuan mengetahui kelayakan video sebagai media pembelajaran pada submateri Sistem Endokrin kelas XI SMA. Penelitian menggunakan metode penelitian deskriptif. Tahapan penelitian meliputi tahap penyusunan materi isi media video dan validasi media video. Validasi dilakukan oleh lima validator. Instrumen penelitian menggunakan lembar validasi. Penilaian lembar validasi menggunakan skala Likert. Aspek yang dinilai yaitu aspek format, isi, dan bahasa. Data dianalisis menggunakan formula Lawshe. Hasil validasi menunjukkan rata-rata CVR pada aspek penilaian format, isi, dan bahasa lebih besar dari batas minimum Lawshe. Berdasarkan hasil penelitian, maka disimpulkan bahwa media video dapat digunakan sebagai media pembelajaran pada submateri Sistem Endokrin pada kelas XI SMA.
\end{abstract}

Kata Kunci: kelayakan media; media pembelajaran; video pembelajaran.

\begin{abstract}
The research aimed to determine the feasibility of video as a learning medium in the Endocrine System submaterial in class XI senior high school. The research used descriptive method. The research stages include the stage of compiling the video media content material and the video media validation stage. Validation was carried out by five validators. The research instrument used a validation sheet. The validation sheet assessment used a Likert scale. The aspects that assessed were format, content, and language. Data were analyzed using Lawshe's formula. The validation results showed that the average CVR in the aspect of format, content, and language assessment was greater than the Lawshe minimum limit. Based on the results of the study, it can be concluded that video media can be used as a learning medium in the Endocrine System submaterial in class XI senior high school.
\end{abstract}

Keywords: media eligibility; learning media; tutorial video.

\section{PENDAHULUAN}

Media merupakan alat bantu yang mampu menunjang pembelajaran, dimana didalamnya terkandung informasi yang dapat disalurkan melalui pengajar kepada peserta didik sehingga dapat menumbuhkan motivasi belajar, merangsang pikiran, perhatian, minat, dan perasaan peserta didik agar memudahkan pencapaian dalam tujuan pembelajaran yang telah dirumuskan dan meningkatkan hasil belajar 
(Setiawan, 2021; Arpan \& Sadikin, 2020; Sipayung et al., 2020; Budiman \& Nurbani, 2019; Pratama, 2018; Matsun et al., 2018; Matrona, 2016; Buchori \& Rina, 2015; Steffi, 2015; Falahudin, 2014; Purwono et al., 2014; Arief et al., 2012). Pembelajaran menggunakan media dapat membangun sebuah persepsi pembelajaran yang sama pada setiap peserta didik, sehingga dalam memahami materi pelajaran tidak akan terjadi suatu kesalahpahaman (Primasari et al., 2014; Utomo et al., 2018). Namun, media yang dapat digunakan sebagai media pembelajaran adalah media yang sudah dinilai dan dinyatakan layak (Sukadi \& Khaerul, 2020; Panjaitan et al., 2019; Adriani \& Sabeki, 2018; Apriani et al., 2018; Faramita et al., 2018; Sari et al., 2018; Utami et al., 2018; Wedyawati \& Lisa, 2018; Qamariah et al., 2017; Matsun, 2015; Darmawan, 2014).

Berdasarkan hasil wawancara terhadap tiga guru Biologi SMA kelas XI di Kota Pontianak, didapatkan informasi bahwa submateri Sistem Endokrin memiliki tingkat ketercapaian yang tergolong rendah jika dibandingkan dengan materimateri lain. Hal tersebut karena submateri Sistem Endokrin cenderung memiliki konsep abstrak sehingga tidak dapat diamati secara langsung dan diperlukan visualisasi dalam penyampaian materinya. Berdasarkan hasil wawancara juga diketahui bahwa hanya satu guru yang menggunakan media dalam menunjang pembelajaran Sistem Endokrin yaitu menggunakan media PowerPoint dengan metode ceramah. Media PowerPoint sendiri cenderung menjadikan peserta didik menjadi lebih pasif karena hanya menerima penjelasan yang disampaikan oleh guru (Simamora \& Mukhtar, 2015).

Salah satu media yang dapat menvisualisasikan konsep secara konkret adalah media video (Yendrita \& Syafitri, 2019; Kurniawan \& Soeprajitno, 2017). Video juga dapat menyajikan pesan pembelajaran berupa prosedur, prinsip, dan teori aplikasi pengetahuan yang mampu membangkitkan pemahaman peserta didik pada suatu materi pembelajaran melalui suara dan gambar (Yuliyanto et al., 2018; Noviyanto et al., 2015). Penggunaan suara dan gambar dalam tampilan video dapat membantu informasi masuk melalui telinga dan mata dan dengan menggunakan media video peserta didik merasa seolah terlibat didalamnya sehingga mampu meningkatkan pemahaman siswa (Nurrita, 2018; Izzudin et al., 
2013; Kurniasih \& Setiawan, 2013). Manfaat lainnya dari media video pembelajaran yaitu media video juga akan menambah efektivitas ruang, waktu, serta penyampaian pesan yang lebih efisien dan guru dapat mengkomunikasikan materi dengan cepat (Megawati, 2017; Anshor et al., 2015).

Hasil penelitian terdahulu menunjukkan bahwa video pembelajaran merupakan sumber belajar yang mampu menarik dan meningkatkan keaktifan peserta didik pada proses belajar-mengajar (Erniasih et al., 2018; Purwanto \& Rizki, 2015). Media video yang dikembangkan dapat membantu meningkatkan pemahaman dan hasil belajar dari peserta didik (Gazali \& Nadhatain, 2019; Kurniawan \& Soeprajitno, 2017; Handziko \& Suyanto, 2015; Luqman et al., 2013). Berdasarkan uraian tersebut, maka penelitian bertujuan untuk mengetahui kelayakan video sebagai media pembelajaran pada submateri Sistem Endokrin kelas XI SMA.

\section{METODE}

Metode penelitian yang digunakan adalah metode deskriptif. Tahapan penelitian ada dua, yaitu tahap penyusunan video pembelajaran dan validasi media video. Sebelum tahap penyusunan video dilakukan persiapan alat dan bahan. Alat yang digunakan adalah laptop dengan aplikasi Videoscibe dan Animiz. Bahan-bahan yang digunakan adalah silabus Kurikulum 2013, ringkasan submateri Sistem Endokrin dari beberapa buku penunjang pembelajaran, serta gambar/foto yang berkaitan dengan materi.

Tahap penyusunan video. Kegiatan yang dilakukan adalah menyusun konsep isi pada media video. Isi pada media video terdiri dari judul, logo universitas, kompetensi dasar, tujuan pembelajaran, uraian submateri Sistem Endokrin yang meliputi kelenjar pada sistem endokrin, karakteristik kelenjar endokrin, hormon yang dihasilkan kelenjar endokrin, penyakit atau gangguan yang bisa terjadi pada organ sistem endokrin, serta kajian pemanfaatan tumbuhan obat berkhasiat antihiperglikemik. Setelah penyusunan konsep dilakukan, maka dilanjutkan proses editing media video pembelajaran yang meliputi penyesuaian warna tulisan pada video dengan background, penambahan gambar/foto dan 
animasi, serta pemilihan backsound. Media video kemudian divalidasi dan dilakukan revisi berdasarkan saran validator.

Validasi video dilakukan oleh 5 validator yang terdiri dari 2 dosen dari jurusan PMIPA FKIP Universitas Tanjungpura, serta 3 guru Biologi SMA kelas XI. Lembar validasi media video dimodifikasi dan dikembangkan dari buku Arsyad (2014). Validasi pada media video pembelajaran meliputi 3 aspek, yaitu aspek format, isi, dan bahasa yang teridiri dari 11 kriteria penilaian. Pengukuran instrumen validasi media video menggunakan skala Likert, yaitu Sangat Baik (SB) bernilai 4, Baik (B) bernilai 3, Kurang Baik (KB) bernilai 2, dan Tidak Baik (TB) bernilai 1. Setelah video selesai divalidasi oleh 5 validator, data yang diperoleh dianalisis dengan formula Lawshe yaitu Content Validity Ratio (CVR) dan Content Validity Index (CVI).

Analisis data dilakukan dengan beberapa langkah, yaitu dengan memasukkan data ke tabel, mencari rata-rata dari setiap kriteria penilaian, mencari rata-rata setiap aspek penilaian, mencari rata-rata total dari ketiga aspek, dan menentukan kategori kevalidan dengan membandingkan rata-rata total dengan nilai kriteria kevalidan. Apabila pada akhir perhitungan skor CVR memenuhi nilai batas minimum, yaitu sebesar 0,99, maka video pembelajaran dinyatakan valid atau layak digunakan (Lawshe, 1975). Analasis data hasil validasi menggunakan rumus (1) (Lawshe, 1975).

$$
\mathrm{CVR}=\frac{\mathrm{Ne}-\frac{N}{2}}{\frac{N}{2}}
$$

Keterangan: Ne adalah jumlah dari ahli yang menyatakan kevalidan media (dianggap setuju atau sangat setuju jika memberikan skor 3 atau 4, jika kurang dari 3, maka dianggap validator tidak menyetujui kevalidan); $\mathrm{N}$ adalah jumlah dari anggota tim ahli atau validator.

Langkah selanjutnya apabila nilai dari CVR sudah didapatkan, maka akan dilakukan perhitungan nilai CVI untuk menggambarkan pada instrumen bahwa butir-butir instrumen secara keseluruhan memiliki validitas isi yang baik. Rumus CVI yang digunakan adalah rumus (2) (Lawshe, 1975). 


$$
\mathrm{CVI}=\frac{\sum C V R}{\sum n}
$$

Keterangan: $\sum C V R$ adalah jumlah dari CVR seluruh kriteria; $\sum$ n adalah jumlah kriteria.

\section{HASIL DAN PEMBAHASAN}

Berdasarkan hasil penilaian validator diketahui bahwa hasil validasi media video pembelajaran mendapatkan nilai CVR 1,00 pada setiap aspek. Secara keseluruhan ketiga aspek tersebut mendapatkan nilai CVI 1,00 yang artinya lebih besar dari batas minimum Lawshe yaitu 0,99. Berdasarkan perolehan nilai hasil validasi bermakna bahwa media valid sehingga dapat digunakan sebagai media pembelajaran pada submateri Sistem Endokrin kelas XI (Lawshe, 1975).

Aspek format memiliki enam kriteria. Aspek format untuk kriteria pertama adalah menampilkan gerakan. Hasil validasi diperoleh nilai CVR sebesar 1,00 sehingga dinyatakan valid. Video dalam penelitian menampilkan transisi yang baik dari animasi, animasi bergerak menunjukkan bagian dari kelenjar endokrin, sehingga dapat membantu peserta didik mengingat letak dari kelenjar endokrin. Video adalah media menampilkan visual dan gambar, sehingga pengolahan informasi akan muncul dalam memori peserta didik (Sukiman, 2012). Aspek format untuk kriteria kedua adalah menampilkan gambar yang nyata. Hasil validasi diperoleh nilai CVR sebesar 1,00 sehingga dinyatakan valid. Video dalam penelitian menampilkan berbagai gambar yang terkait dengan materi seperti pengidap penyakit atau mengalami gangguan hormon yang dapat menambah pengetahuan dengan mendapatkan gambaran langsung seperti apa penyakit atau gangguan pada Sistem Endokrin. Gambar yang disajikan dalam video hendaknya lebih bervariasi agar penonton tidak cepat merasa bosan (Prastowo, 2014).

Aspek format untuk kriteria ketiga adalah penggunaan ukuran huruf yang sesuai. Hasil validasi diperoleh nilai CVR sebesar 1,00 sehingga dinyatakan valid. Video dalam penelitian menggunakan ukuran huruf disesuaikan dengan kebutuhan penonton agar tetap terjangkau oleh seluruh peserta didik di dalam kelas dan menggunakan jenis huruf yang tegas agar lebih mudah dilihat. Tulisan 
dalam sebuah media harus lebih dipertimbangkan agar mudah dibaca oleh peserta didik, maka sebaiknya tulisan pada media disusun dengan menggunakan huruf yang tidak terlalu kecil (Fadli et al., 2017).

\section{Tabel 1 Hasil Analisis Validasi Media Video Pembelajaran Submateri Sistem} Endokrin

\begin{tabular}{|c|c|c|c|c|c|c|c|}
\hline \multirow{2}{*}{ Aspek } & \multirow{2}{*}{ Kriteria } & \multicolumn{4}{|c|}{ Validator } & \multirow{2}{*}{ CVR } & \multirow{2}{*}{ Ket } \\
\hline & & 1 & 23 & 34 & 5 & & \\
\hline \multirow{6}{*}{ Format } & $\begin{array}{l}\text { Menampilkan } \\
\text { gerakan. }\end{array}$ & 4 & 44 & 44 & 3 & 1,00 & Valid \\
\hline & $\begin{array}{l}\text { Menampilkan } \\
\text { gambar yang nyata. }\end{array}$ & 4 & 44 & 44 & 4 & 1,00 & Valid \\
\hline & $\begin{array}{l}\text { Penggunaan ukuran } \\
\text { huruf yang sesuai. }\end{array}$ & 3 & 44 & 44 & 4 & 1,00 & Valid \\
\hline & $\begin{array}{l}\text { Kesesuaian } \\
\text { tampilan, warna, } \\
\text { gambar, dan tulisan. }\end{array}$ & 3 & 44 & $4 \quad 4$ & 4 & 1,00 & Valid \\
\hline & $\begin{array}{l}\text { Keseimbangan tata } \\
\text { letak tulisan. }\end{array}$ & 3 & & & 4 & 1,00 & Valid \\
\hline & $\begin{array}{l}\text { Video disusun secara } \\
\text { sistematis. }\end{array}$ & 3 & 44 & $4 \quad 4$ & 3 & 1,00 & Valid \\
\hline \multicolumn{6}{|c|}{ Nilai rata-rata pada aspek format } & 1,00 & Valid \\
\hline \multirow{4}{*}{ Isi } & $\begin{array}{l}\text { Kelengkapan } \\
\text { penyajian informasi } \\
\text { Sistem Endokrin. }\end{array}$ & 4 & 43 & 34 & 4 & 1,00 & Valid \\
\hline & $\begin{array}{l}\text { Uraian materi video } \\
\text { sesuai dengan tujuan } \\
\text { pembelajaran. }\end{array}$ & 3 & 44 & 44 & 3 & 1,00 & Valid \\
\hline & $\begin{array}{l}\text { Kemudahan } \\
\text { memahami materi } \\
\text { yang disajikan. }\end{array}$ & 3 & 34 & 43 & 3 & 1,00 & Valid \\
\hline & \multicolumn{5}{|c|}{ Nilai rata-rata aspek isi } & 1,00 & Valid \\
\hline & $\begin{array}{l}\text { Bahasa yang } \\
\text { digunakan mudah } \\
\text { dipahami. }\end{array}$ & 3 & 34 & 44 & 3 & 1,00 & Valid \\
\hline Bahasa & $\begin{array}{l}\text { Kelengkapan kalimat } \\
\text { dan informasi yang } \\
\text { dibutuhkan peserta } \\
\text { didik. }\end{array}$ & 3 & 34 & 44 & 4 & 1,00 & Valid \\
\hline \multicolumn{6}{|c|}{ Nilai rata-rata aspek bahasa } & 1,00 & Valid \\
\hline \multicolumn{6}{|c|}{ CVI } & 1,00 & Valid \\
\hline
\end{tabular}


Aspek format untuk kriteria keempat adalah kesesuaian tampilan, warna, dan tulisan. Hasil validasi diperoleh nilai CVR sebesar 1,00 sehingga dinyatakan valid. Media video dalam penelitian menggunakan warna-warna yang kontras antara background, gambar, dan tulisan sehingga membuat teks tulisan dan gambar yang ditampilkan dalam video terlihat lebih jelas. Saran dari validator pada warna tulisan judul video agar dibuat lebih tegas warna tulisannya. Perbaikan pada warna tulisan dapat dilihat di Gambar 1. Warna yang digunakan pada media akan mengarahkan perhatian peserta didik dalam membedakan setiap komponen yang ditekankan pada materi pembelajaran (Mumtahanah, 2014).

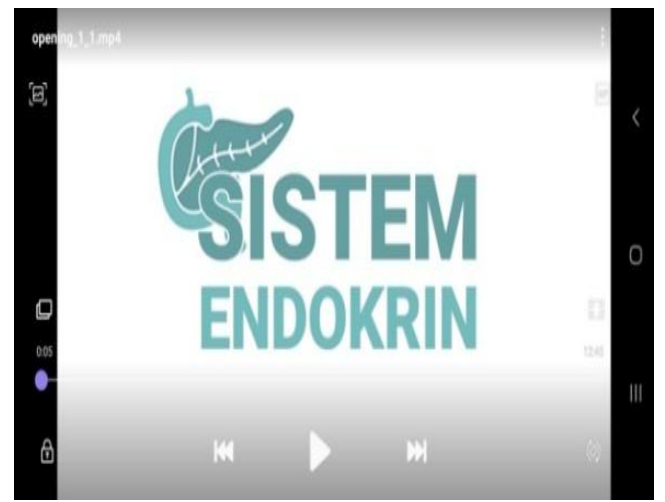

(a)

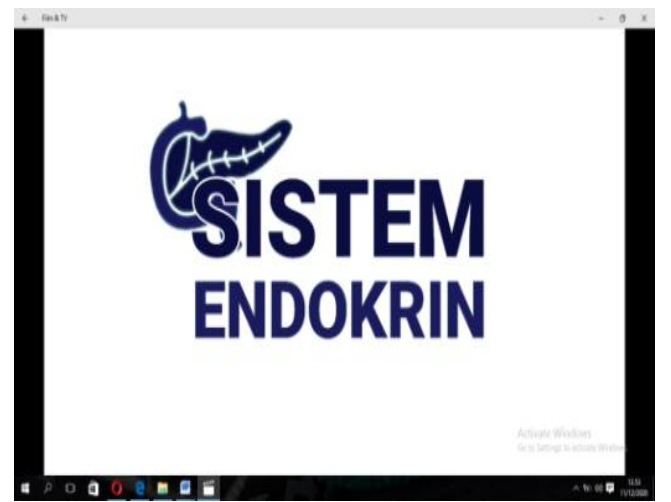

(b)

Gambar 1 Perbaikan pada Warna Judul Sistem Endokrin (a) Sebelum Perbaikan (b) Sesudah Perbaikan

Aspek format untuk kriteria kelima adalah tata letak tulisan yang seimbang. Hasil validasi diperoleh nilai CVR sebesar 1,00 sehingga dinyatakan valid. Tata letak pada video disesuaikan dengan gambar, animasi, dan teks dalam video agar tidak terlihat tumpang tindih pada tampilan video. Aspek format untuk kriteria keenam yaitu video dibuat dan disusun dengan sistematis. Hasil validasi diperoleh nilai CVR sebesar 1,00 sehingga dinyatakan valid. Penyusunan video disusun secara urut yaitu meliputi judul, kompetensi dasar, tujuan pembelajaran, submateri Sistem Endokrin, tambahan informasi berupa hasil penelitian, dan daftar pustaka. Apabila terdapat ketidaksesuaian antara kriteria-kriteria tampilan pada media video akan kurang informatif dan tidak menarik. Keterpaduan pada semua bagian elemen visual akan berfungsi bersama-sama sehingga menjadikan media lebih menarik ketika diamati (Arsyad, 2014). 
Aspek isi terdiri dari 3 kriteria. Aspek isi untuk kriteria pertama adalah kelengkapan penyajian informasi submateri Sistem Endokrin. Hasil validasi diperoleh nilai CVR sebesar 1,00 sehingga dinyatakan valid. Informasi dalam video disajikan sesuai berdasarkan pada kompetensi dasar dan perumusan tujuan pembelajaran dan dinilai lengkap oleh validator. Aspek isi untuk kriteria kedua adalah kesesuaian uraian materi pada video dengan tujuan pembelajaran. Hasil validasi diperoleh nilai CVR sebesar 1,00 sehingga dinyatakan valid. Materi yang terdapat dalam video sudah sesuai terhadap tujuan pembelajaran yang dibuat sehingga ketercapaian dalam pembelajaran diharapkan dapat meningkat. Aspek isi untuk kriteria ketiga adalah kemudahan dalam memahami materi yang ditampilkan pada video.

Hasil validasi diperoleh nilai CVR sebesar 1,00 sehingga dinyatakan valid. Materi dalam video disampaikan dengan menggunakan kalimat yang jelas dan padat, serta materi dalam video juga sudah dirangkum dari beberapa sumber sehingga dapat memudahkan peserta didik dalam memahami materi yang disampaikan. Media video mempunyai manfaat-manfaat yang dapat membangkitkan motivasi belajar peserta didik. Hal tersebut membuat materi akan lebih mudah dipahami serta mampu mengubah perilaku peserta didik agar lebih mudah untuk berkonsentrasi, memberikan umpan balik, menambah wawasan, dan menambah pengalaman (Resta et al., 2013).

Aspek bahasa terdiri dari 2 kriteria. Aspek bahasa untuk kriteria pertama adalah penggunaan bahasa yang mudah. Hasil validasi diperoleh nilai CVR sebesar 1,00 sehingga dinyatakan valid. Bahasa yang digunakan dalam video sesuai dengan tata bahasa Indonesia yang baik dan benar, serta bahasanya lugas sehingga memudahkan peserta didik untuk memahami materi. Penggunaan bahasa yang jelas dalam penyajian media akan menghasilkan media yang baik (Asyhar, 2012). Aspek bahasa untuk kriteria kedua adalah kelengkapan kalimat dalam informasi yang diperlukan peserta didik. Hasil validasi diperoleh nilai CVR sebesar 1,00 sehinggan dinyatakan valid. Media video menampilkan kalimat yang sinkron antara satu dan yang lain, serta mampu memberikan informasi tambahan kepada peserta didik. Perlu diperhatikan bahwa media video memerlukan 
sinkronisasi antara suara, gambar, dan teks yang ditampilkan sehingga menjadikannya menarik untuk peserta didik dalam proses belajar (Robert, 2013).

\section{SIMPULAN}

Berdasarkan hasil validasi media video yang dilakukan 5 validator, setiap aspek yang diamati yaitu aspek format, isi, dan bahasa diperoleh nilai CVR dan CVI yang lebih besar dari batas minimum Lawhe sehingga disimpulkan bahwa media video pembelajaran submateri Sistem Endokrin dinyatakan valid atau layak digunakan sebagai media pembelajaran.

\section{DAFTAR PUSTAKA}

Adriani, N., \& Sabeki, A. W. (2018). Tingkat Validasi Media Pembelajaran Kimia Berbasis Android Validity of Android-Based Chemistry Learning Media. Jurnal Zarah, 6(2), 76-80. https://doi.org/10.31629/zarah.v6i2.705.

Anshor, S., Sugiyanta, I. G., \& Utami, R. K. S. (2015). Pengggunaan Media Pembelajaran Berbasis Video terhadap Aktivitas dan Hasil Belajar Geografi. Jurnal Penelitian Geografi, 3(7), 1-10.

Apriani, A., Daningsih, E., \& Yokhebed, Y. (2018). Kelayakan Video Tutorial Pembuatan Donat Jahe Submateri Peran Tumbuhan di Bidang Ekonomi. Edukasi: $\quad$ Jurnal Pendidikan, $\quad$ 16(2), 255-266. http://dx.doi.org/10.31571/edukasi.v16i2.978.

Arief, S. S., Rahardjo, R., \& Anung, H. R. (2012). Media Pendidikan Pengertian, Pengembangan, dan Pemanfaatan. Jakarta: PT Rajagrafindo Persada.

Arpan, M., \& Sadikin, S. (2020). Media Pembelajaran Interaktif Perangkat Keras Komputer. INVOTEK: Jurnal Inovasi Vokasional dan Teknologi, 20(2), 4350. https://doi.org/10.24036/invotek.v20i2.741.

Arsyad, A. (2014). Media Pembelajaran. Jakarta: Raja Grafindo Persada. Asyhar, R. (2012). Kreatif Mengembangkan Media Pembelajaran. Jakarta: GP Press. 
Buchori, A., \& Rina, D. S. (2015). Development Learning Model of Character Education Through E-Comic in Eementary School. International Journal of Education and Research, 3(9), 369-386.

Budiman, R., \& Nurbani, N. (2019). Pengembangan Media Pembelajaran Pengenalan Sistem Operasi Berbasis Android. Edukasi: Jurnal Pendidikan, 17(2), 183-197. http://dx.doi.org/10.31571/edukasi.v17i2.1305.

Darmawan, H. (2014). Peningkatan Kreatifitas Mahasiswa dalam Merancang Media Pembelajaran Multimedia IPA Berbasis Animasi melalui Model Cooperative Learning. Edukasi: Jurnal Pendidikan, 12(2), 193-204. http://dx.doi.org/10.31571/edukasi.v12i2.155.

Erniasih, U., Suwito, E. P., \& Atno, A. (2018). Perbedaan Hasil Belajar dengan Menggunakan Media Video Edukasi dan Media Video Dokumenter pada Pembelajaran Sejarah di SMA N 12 Semarang Tahun Ajaran 2017/2018. Indonesian Journal of History Education, 6(2), 162-171.

Fadli, R., Sartono, N., \& Suryanda, A. (2017). Pengembangan Kamus Berbasis Sistem Operasi Telepon Pintar pada Materi Biologi SMA kelas XI. Jurnal Pendidikan Matematikan dan IPA, 8(2), 10-17. http://dx.doi.org/10.26418/jpmipa.v8i2.21171.

Falahudin, I. (2014). Pemanfaatan Media dalam Pembelajaran. Jurnal Lingkar Widyaiswara (JLW), 1(4), 104-117.

Faramita, G., Daningsih, E., \& Yokhebed, Y. (2018). Kelayakan Film Dokumenter Pembuatan Bingka Pepaya Submateri Peran Tumbuhan di Bidang Ekonomi. Edukasi: Jurnal Pendidikan, 16(2), 267-280. http://dx.doi.org/10.31571/edukasi.v16i2.1025.

Gazali, Z., \& Nadhatain, H. (2019). Pengembangan Media Pembelajaran Berbasis Video pada Materi Biologi Sel untuk Siswa SMA/MA Kelas XI IPA. Jurnal Pendidikan Mandala, $\quad$ 23(5), http://dx.doi.org/10.36312/jupe.v4i5.867.

Handziko, R. C., \& Suyanto, S. (2015). Pengembangan Video Pembelajaran Suksesi Ekosistem untuk Meningkatkan Motivasi dan Penguasaan Konsep 
Mahasiswa. Jurnal Inovasi Pendidikan IPA, 1(2), 212-224. https://doi.org/10.21831/jipi.v1i2.7508.

Izzudin, A. M., Masugino, M., \& Suharmanto, A. (2013). Efektivitas Penggunaan Media Pembelajaran Video Interaktif untuk Meningkatkan Hasil Belajar Praktik Service Engine dan Komponen-Komponennya. Automotive Science and Education Journal, 2(2), 1-8.

Kurniasih, F., \& Setiawan, N. (2013). Pengembangan Media Film Dokumeter sebagai Pendukung Pembelajaran Akuntansi Pokok Bahasan Siklus Akuntansi Perusahaan Dagang Bagi Siswa SMK Kelas X Akuntansi. Kajian Pendidikan Akuntansi Indonesia, 2(1), 21-36.

Kurniawan, M. R., \& Soeprajitno. (2017). Pengembangan Media Video Pembelajaran Materi Pokok Invertebrata Mata Pelajaran Biologi untuk Meningkatkan Hasil Belajar Siswa Kelas X IPA di SMA Persatuan Tulangan Sidoarjo. Jurnal Mahasiswa Teknologi Pendidikan, 8(2), 1-5.

Lawshe, C. H. (1975). A Quantitative Approach to Content Validity. A paper presented at Content Validity II, a conference held at Bowling Green State University July 18, $1975 . \quad$ https://doi.org/10.1111/j.17446570.1975.tb01393.x

Luqman, H., Karyanto, P., \& Maridi, M. (2013). Pengaruh Model Pembelajaran Based Instruction Disertai Media Audio Visual terhadap Hasil Belajar Biologi Tahun Pelajaran 2011/2012. Jurnal Pendidikan Biologi, 5(1), 49-58. Matrona, M. (2016). Upaya Meningkatkan Minat Belajar PKn Siswa dengan Menggunakan Media Visual di Kelas 1 SD Negeri 59 KM 2 Ngabang Kabupaten Landak. Edukasi: Jurnal Pendidikan, 14(1), 83-93. http://dx.doi.org/10.31571/edukasi.v14i1.287.

Matsun, M. (2015). Pengembangan Media Pembelajaran Elektronika Lanjut pada Materi Gerbang Logika Menggunakan Adobe Flash. Jurnal Pendidikan Informatika dan Sains, 4(1), 99-111. http://dx.doi.org/10.31571/saintek.v4i1.9.

Matsun, M., Ramadhani, D., \& Lestari, I. (2018). Perancangan Media Pembelajaran Listrik Magnet Berbasis Android di Program Studi 
Pendidikan Fisika IKIP PGRI Pontianak. Jurnal Pendidikan Informatika dan Sains, 7(1), 107-117. http://dx.doi.org/10.31571/saintek.v7i1.774.

Megawati. (2017). Pengembangan Media Pembelajaran Video Berbasis Inkuiri untuk Meningkatkan Hasil Belajar Siswa pada Materi Keseimbangan Ekosistem. Prosiding Seminar Nasional Tahunan Fakultas Ilmu Sosial Universitas Negeri Medan Tahun 2017.

Mumtahanah, N. (2014). Penggunaan Media Visual dalam Pembelajaran PAI. $A L$ HIKMAH Jurnal Studi Keislaman, 4(1), 92-104. https://doi.org/10.36835/hjsk.v4i1.511.

Noviyanto, T., Juanengsih, N., \& Rosyidatun, E. S. (2015). Penggunaan Media Video Animasi Sistem Pernapasan Manusia untuk Meningkatkan Hasil Belajar Biologi. EDUSAIN, 7(1), 57-63.

Nurrita, T. (2018). Pengembangan Media Pembelajaran untuk Meningkatkan Hasil Belajar Siswa. Misykat, 3(1), 171-187. http://dx.doi.org/10.33511/misykat.v3n1.171.

Panjaitan, R. G. P., Lijana, \& Wahyuni, E. S. (2019). The Use of Comic as a Learning Medium of Ecology. Unnes Science Education Journal, 8(1), 4145. https://doi.org/10.15294/usej.v8i1.23194.

Pratama, A. (2018). Perancangan Media Pembelajaran Cross-Platform Instalasi Software pada Paket Keahlian Teknik Komputer dan Jaringan. Jurnal Pendidikan Informatika dan Sains, 7(1), 1-10. http://dx.doi.org/10.31571/saintek.v7i1.678.

Prastowo, A. (2014). Pengembangan Bahan Ajar Tematik. Jakarta: Kencana Predana Media Group.

Primasari, R., Zulfiani, Z., \& Herlayanti, Y. (2014). Penggunaan Media Pembelajaran di Madrasah Aliah Negeri se-Jakarta Selatan. EDUSAINS, 6(1), 68-72. https://doi.org/10.15408/es.v6i1.1101.

Purwono, J., Sri, Y., \& Sri, A. (2014). Penggunaan Media Audio-Visual pada Mata Pelajaran Ilmu Pengetahuan Alam di Sekolah Menengah Pertama Negeri 1 Pacitan. Jurnal Teknologi Pendidikan dan Pembelajaran, 2(2), 127-44. 
Purwanto, Y., \& Rizki, S. (2015). Pengembangan Bahan Ajar Berbasis Kontekstual pada Materi Himpunan Berbantu Video Pembelajaran. AKSIOMA Journal of Mathematics Education, 4(1), 67-77. http://dx.doi.org/10.24127/ajpm.v4i1.95.

Qamariah, W., Daningsih, E., \& Yokhebed, Y. (2017). Kelayakan Animasi Stop Motion Pembuatan Cake Pepaya Submateri Peran Tumbuhan di Bidang Ekonomi. Jurnal Pendidikan Informatika dan Sains, 6(2), 267-279. http://dx.doi.org/10.31571/saintek.v6i2.682.

Resta, L. I., Fauzi, A., \& Yulkifli. (2013). Pengaruh Pendekatan Pictorial Riddle Jenis Video terhadap Hasil Belajar Siswa dalam Pembelajaran Inkuiri pada Materi Gelombang Terintegrasi Bencana Tsunami. Jurnal Pillar of Physics Education, 1(1), 17-22.

Robert, R. (2013). Pembuatan Materi Belajar dengan Pendekatan Video-Based Learning. Jurnal TIME, 2(2), 39-41.

Sari, F., Darma, Y., \& Dafrita, I. (2018). Pengembangan Media Pembelajaran Powerpoint Integrasi Geogebra untuk Meningkatkan Kemampuan Representasi Matematis dalam Materi Refleksi. Edukasi: Jurnal Pendidikan, 16(2), 281-289. http://dx.doi.org/10.31571/edukasi.v16i2.1026.

Setiawan, W. (2021). Pengembangan Media Pembelajaran Berbasis Android dengan App Inventor pada Materi Perangkat Lunak Pengolah Kata. JUWARA: Jurnal Wawasan dan Aksara, 1(1), 37-46.

Simamora, A. M., \& Mukhtar. (2015). Pengembangan Media Pembelajaran Kalimat Efektif pada Pelajaran Bahasa Indonesia. Jurnal Teknologi Informasi dan Komunikasi dalam Pendidikan, 2(2), 201-214. https://doi.org/10.24114/jtikp.v2i2.3296.

Sipayung, M., Chastanti, I., Harahap, R. D., \& Sari, N. F. (2020). Pengembangan Media Pembelalajaran Interaktif Berbasis Adobe Flash terhadap Materi Sistem Pernapasan di SMA Negeri 1 Aekkuasan Kabupaten Asahan. Jurnal Pendidikan Informatika dan Sains, 9(1), 59-65. http://dx.doi.org/10.31571/saintek.v9i1.1228. 
Steffi, A., \& Muhammad, T. S. (2015). Pemanfaatan Media Pembelajaran Berbasis Teknologi Informasi bagi Siswa Kelas X SMA Ananda Batam. CBIS Journal, 3(2), 78-90.

Sukadi, E., \& Khaerul, M. (2020). Pengembangan LKS Berbasis POE terhadap Pemahaman Konsep Siswa SMA Kelas X Pokok Bahasan Gerak Lurus. Jurnal Pendidikan Informatika dan Sains, 9(2), 90-102. http://dx.doi.org/10.31571/saintek.v9i2.2377.

Sukiman. (2012). Pengembangan Media Pembelajaran. Yogyakarta: Pustaka Insan Madani.

Utami, R., Daningsih, E., \& Marlina, R. (2018). Kelayakan CD Interaktif pada Submateri Organ Tumbuhan di Kelas XI SMA. Edukasi: Jurnal Pendidikan, 16(2), 210-221. http://dx.doi.org/10.31571/edukasi.v16i2.949.

Utomo, C. B., Amin, S., \& Ria, T. N. (2018). Wayang Suluh as Learning Media in Teaching History in High School. Jurnal Paramita, 28(1), 105-111. https://doi.org/10.15294/paramita.v28i1.13926.

Wedyawati, N., \& Lisa, Y. (2018). Kelayakan Buku Ajar Mata Kuliah Pembelajaran IPA SD bagi Mahasiswa PGSD. Edukasi: Jurnal Pendidikan, 16(2), 155-168. http://dx.doi.org/10.31571/edukasi.v16i2.943.

Yendrita, Y., \& Syafitri, Y. (2019). Pengaruh Penggunaan Media Video Pembelajaran terhadap Hasil Belajar Biologi. BIOEDUSAINS: Jurnal Pendidikan Biologi dan Sains, 2(1), 26-32. https://doi.org/10.31539/bioedusains.v2i1.620.

Yuliyanto, E., Wijoyo, Y., Istyastono, E. P., \& Hidayah, F. F. (2018). Refleksi Praktikum Kimia Organik Calon Pendidik Kimia Menggunakan Rekaman Video. Jurnal Pendidikan Sains, 6(2), 76-83. https://doi.org/10.26714/jps.6.2.2018.76-83. 